NosHe-ye Hatṭī va fehrest-negārī-ye ān dar İrān : Majmū'e-ye maqālāt va jostār-hā be pās-e zaḥamāte sī-sāle-ye Frānsīs Rišār nosHुe-šenās-e barjaste-ye farānsavī [Manuscript and its Cataloguing in Iran : A Collection of Articles Dedicated to Francis Richard]. Majmū'e-ye Jašn-nāme-hā, 1, Mirāt-e Maktūb, 132, Tehrān, 1384/2005, 198 p.

\title{
Maria Szuppe
}

\section{OpenEdition}

\section{Journals}

Édition électronique

URL : http://journals.openedition.org/abstractairanica/9622

DOI : 10.4000/abstractairanica.9622

ISSN : 1961-960X

Éditeur :

CNRS (UMR 7528 Mondes iraniens et indiens), Éditions de l'IFRI

Édition imprimée

Date de publication : 15 mai 2007

ISSN : 0240-8910

\section{Référence électronique}

Maria Szuppe, « Noshe-ye hatțī va fehrest-negārī-ye ān dar İrān : Majmūe-ye maqālāt va jostār-hā be pās-e zahamāte sī-sāle-ye Frānsīs Rišār noshe-šenās-e barjaste-ye farānsavī [Manuscript and its Cataloguing in Iran : A Collection of Articles Dedicated to Francis Richard]. Majmū'e-ye Jašn-nāme-hā, 1, Mirāte-e Maktūb, 132, Tehrān, 1384/2005, 198 p. », Abstracta Iranica [En ligne], Volume 28 | 2007, document 15, mis en ligne le 18 septembre 2007, consulté le 25 septembre 2020. URL : http:// journals.openedition.org/abstractairanica/9622 ; DOI : https://doi.org/10.4000/abstractairanica.9622 
NosHe-ye Hatțī va fehrest-negārī-ye ān dar İrān : Majmū'e-ye maqālāt va jostār-hā be pās-e zahamāt-e sī-sāleye Frānsīs Rišār nosHèe-šenās-e barjaste-ye farānsavī [Manuscript and its Cataloguing in Iran : A Collection of Articles Dedicated to Francis Richard]. Majmū'e-ye Jašnnāme-hā, 1, Mirāte-e Maktūb, 132, Tehrān, 1384/2005, 198 p.

Maria Szuppe

Volume de mélanges, présenté en hommage à Francis Richard par les chercheurs iraniens pour l'intégralité de son œuvre sur la culture et l'histoire de l'Iran. L'élégant avant-propos, signé par Akbar İrānī, directeur du Centre de recherches sur le patrimoine écrit (Markaz-e Pažūhešī-ye Mīāt-e Maktūb), esquisse les directions principales de la recherche de F. Richard dont les travaux et la personnalité jouissent d'une grande estime en Iran. Il y est notamment reconnu comme un maître incontesté des études sur la codicologie et l'histoire du livre manuscrit persan : non seulement de nombreux articles, mais aussi ses ouvrages Les splendeurs persanes. Manuscrits $d u$ XII ${ }^{e}$ au XVII siècle, 1997 [voir Abs. Ir. 20-21, c.r. n 28] et Le livre persan, 2003 [voir Abs. Ir. 26, c.r. $\left.\mathrm{n}^{\circ} 17\right]$, ont été traduits en persan. 
2 Le volume est présenté en deux parties. Il s'ouvre par une introduction de l'éditeur A.-R. Rahīmī-Rīse sur l'importance de l'étude des manuscrits en Iran. Suit la biographie succincte de Francis Richard et une liste détaillée de ses publications. Onze contributions (dont certaines sont des rééditions) par des spécialistes iraniens de codicologie, de paléographie et du catalogage, ainsi que par des historiens, sont regroupées selon deux grands domaines : histoire générale, et histoire du catalogage des manuscrits.

3 I. Thèmes généraux et histoire (pp. 29-105) : İraj Afšār, "Sargodašt va sarnevešt-e nosHुe-hā-ye Hatṭī » [Histoire et destinée des manuscrits], pp. 31-47 ; Mohammad-Taqī Dāneš-pažūh, « Negāhī be tārīH -e fehrest-nevīsī dar dowrān-e eslāmī » [Un aperçu de l'histoire du catalogage à l'époque islamique], pp. 49-56; Nūš-Āfarīn Anșārī, « Āmūzeš-e sāzmāndehī-ye nosaH̆-e Hatțī dar Īrān » [L'enseignement du classement des manuscrits en Iran], pp. 57-63 ; Farībā Afkārī, « Pǐšīne-ye āmūzeš-e nosaH̆-e Haț̣ī dar Īrān » [L'historique de l'enseignement de l'étude des manuscrits], pp. 65-71; İraj Afšār, 'Abdallāh Anvār, Seyyed 'Alī Āl-e Dāvūd, « Darbāre-ye tarh-e tamallok-e nosaH-e Hatṭī » [À propos du projet concernant la possession des manuscrits], pp. 73-87; Rasūl Ja'fariyān, « NosHe-ye mohājer : pažūhešĩ darbāre-ye enteqāl-e ketāb-hā-ye kohan-e šìi az sarzamīn-hā-ye 'arabī be İrān dar āgāa-e dowre-ye șafavī » [Les manuscrits immigrés : étude sur les déplacements des livres chiites anciens depuis les pays arabes vers l'Iran à l'époque safavide], pp. 89-105.

II. Catalogage des manuscrits (pp. 107-198) : İraj Afšār, "Tarḥ-e kārt-e barge » [Schéma de la fiche de catalogage], pp. 109-110 ; Moḥammad-Taqī Dāneš-pažūh, « Āyīne fehrest-negārī-ye nosHुe-ye Hatțī » [La pratique du catalogage des manuscrits], pp.111-117; Aḥmad Monzavī, «Šīve-ye fehrest-negārī-ye ketāb-hā-ye Hatṭī » [Méthodes de catalogage des livres manuscrits], pp. 119-136; Aḥmad Monzavī, «Tajrobe-ye yek 'omr fehrest-negārī» [L'expérience d'une vie de catalogage], pp. 137-165 ; «Godašte va ḥāl-e fehrest-negārī » [Le passé et le présent du catalogage], entretien avec MM. Moḥammad-Bāqer Ḥojjatī, Reḍā Ostādī et Aḥmad Aškevarī, pp. 167-198.

\section{INDEX}

Thèmes : 1.2. Recueils d'articles : revues, colloques, ouvrages collectifs

\section{AUTEURS}

MARIA SZUPPE

CNRS / Mondes iranien et indien - Paris 